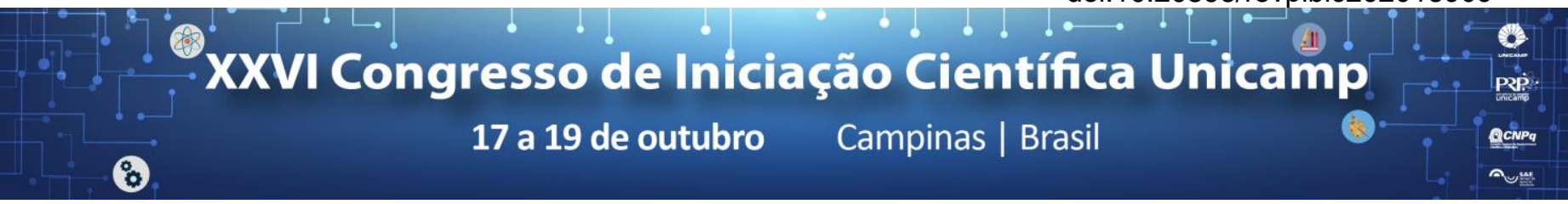

\title{
Diferentes concentrações de ferro na dieta durante a prenhez influenciam na capacidade aeróbia da prole?
}

\section{Lucca Antonio Rodrigues Cavallaro*, Beatriz da Silva Franco, Rosangela Maria Neves Bezerra, Andrea Maculano Esteves.}

\section{Resumo}

A deficiência de ferro (DFe) é frequente em atletas devido à alta demanda de ferro exigida pelos exercícios físicos. No entanto, não está bem esclarecido na literatura se, essas particularidades da relação do padrão de ferro no organismo com a performance, podem ser influenciadas pela epigenética. Assim, nesse trabalho aplicamos diferentes concentrações de ferro na dieta durante a prenhez, divididos em 4 grupos (padrão- $40 \mathrm{mg} / \mathrm{kg}$, restrição- $4 \mathrm{mg} / \mathrm{kg}$, restrição2-4mg/kg e suplementação-100 mg/kg), após o nascimento da prole avaliamos o desempenho físico pelo teste de Lactato Mínimo realizado pelo protocolo de natação. Os resultados sugerem que o grupo de prole de mães restrição de ferro antes e durante a prenhes, obteve uma queda notória em seu desempenho ao longo do experimento.

Palavras-chave: Desempenho físico, concentrações de ferro, lactato mínimo

\section{Introdução}

O ferro é crítico para o metabolismo oxidativo ${ }^{1}$, contudo uma deficiência de ferro (Dfe) pode causar uma redução de fornecimento de oxigênio para os músculos, retardando algumas reações metabólicas, já que perdemos ferro pelo suor ${ }^{2}$. Portanto, a Dfe pode atenuar o desempenho aeróbio ao diminuir o consumo máximo de oxigênio e da capacidade de suportarmos esforço submáximo ${ }^{3}$. A suplementação de ferro pode reverter o quadro de Dfe, e ajudar no exercício físico por causa das suas propriedades ergogênicas ${ }^{4}$. $\mathrm{O}$ objetivo do estudo foi avaliar a capacidade aeróbia da prole de ratas que passaram por diferentes dietas de ferro durante a prenhez, através do teste de Lactato Mínimo.

\section{Resultados e Discussão}

As ratas prenhas foram distribuídas em 4 grupos: 1) prenhes com dieta padrão - 40mg/kg; 2) prenhes com dieta suplementação - $100 \mathrm{mg} / \mathrm{kg}$; 3) prenhes com dieta restrição de ferro - 4mg/kg; 4) prenhes com dieta restrição2 só durante a prenhes - $4 \mathrm{mg} / \mathrm{kg}$. Após o nascimento a prole foi designada aos seus respectivos grupos (PAD, SUP, REST e REST2). $O$ teste de Lactato ${ }^{5}$ Mínimo foi realizado em três momentos: antes de iniciar o treinamento (1 LAC), após quatro semanas de treinamento (2 LAC) e após oito semanas de treinamento (3 LAC). Nos resultados referentes à intensidade obtida no teste de Lactato Mínimo (Figura1) e ao Tempo Limite (figura2), o grupo REST obteve redução estatisticamente significante nos dois últimos testes, 2 LAC, 3 LAC e 2 TL, $3 \mathrm{TL}$ em relação ao teste basal 1 LAC e $1 \mathrm{TL}$ respectivamente.

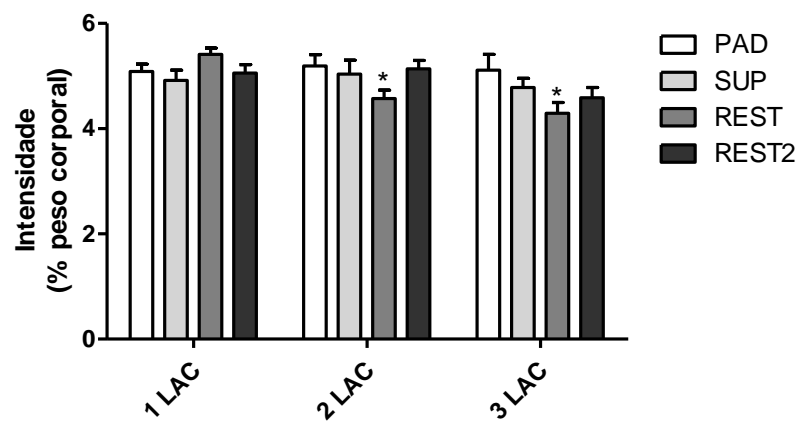

Figura 1. Intensidade da carga (\% peso corporal) obtida através do teste de lactato mínimo em três momentos: basal (1 LAC), após quatro semanas de treinamento (2 LAC) e após oito semanas de treinamento ( 3 LAC). ANOVA para medidas repetidas, post hoc Tukey $(p<0,05)$ *difere do grupo REST no momento 1 LAC.

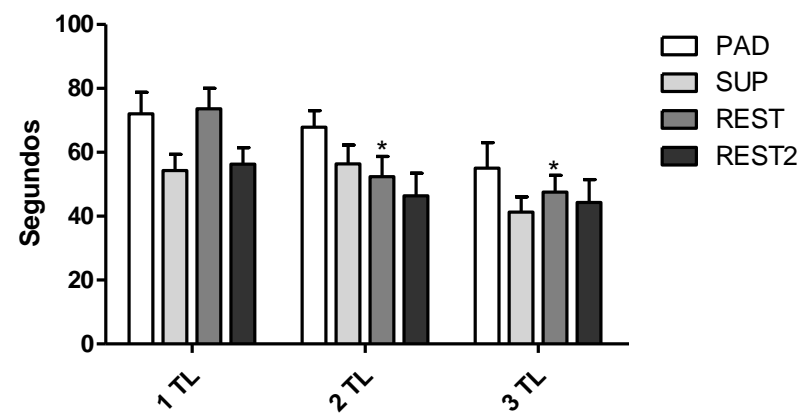

Figura 2. Tempo Limite (segundos) obtido através do teste de lactato mínimo em três momentos: basal (1 TL), após quatro semanas de treinamento (2 TL) e após oito semanas de treinamento (3 TL). ANOVA para medidas repetidas, post hoc Tukey $(p<0,05)$ *difere do grupo REST no momento $1 \mathrm{TL}$.

Estudos demosntram que uma das propriedades do ferro é ser ergogênico, ou seja, melhora o trasnporte de oxigênio para os músculos, portanto o grupo REST apresentou uma queda siginificativa nos valores de lactato em relação a ele mesmo, não conseguindo se aproveitar do ergogênia do ferro, não mantendo uma regularidade nos testes de Lactato Minimo.

\section{Conclusões}

O grupo REST obteve uma queda notória em seu desempenho, podendo ter ocorrido pelo fato da restrição de ferro, e os outros grupos (PAD, SUP e REST2) não tiveram alteração no desempenho ao longo do experimento.

\section{Agradecimentos}

Laboratório do Sono e do Exercício Físico - LASEF e a FAPESP (2017/11167-4) pelo financiamento da pesquisa.

\footnotetext{
${ }^{1}$ Beard JL. J Nutr. 2001, 131, 568-79. discussion 80.

2 Peeling P.; Dawson B.; Goodman C.; Landers G.; Trinder D. European journal of applied physiology. 2008, 103 (4), 381-91.

${ }^{3}$ Haas J. D.; Brownlie T. J Nutr. 2001 131, 676-88. discussion 88-90.

${ }^{4}$ Brutsaert T.D., et al. Am J Clin Nutr. 2003, 77, 441-8.

${ }^{5}$ De Araujo G.G. et al. Eur J Appl Physiol, 2012, v. 112, n. 3, p. 839-52.
} 